\title{
Website Gereja dengan Framework Laravel
}

\author{
Eric Sugiharto Honggara, Departemen Sistem Informasi, Institut Sains dan Teknologi Terpadu \\ Surabaya
}

\begin{abstract}
Abstrak-Salah informasi adalah sebuah hal yang masih sering terjadi karena terlalu banyak sumber informasi dan tidak memiliki sumber informasi acuan yang tepat. Hal ini terjadi pada Gereja Reformed Injili Indonesia di mana jemaat datang pada waktu yang salah untuk mengikuti acara karena informasi yang beredar salah atau telah dirubah karena suatu sebab. Sehingga untuk menyelesaikan masalah tersebut diperlukan sebuah situs web sebagai acuan informasi mengenai kegiatan atau acara pada gereja. Metode pembangunan menggunakan prototype dikarenakan pihak gereja belum pernah membangun situs web dan membutuhkan panduan dalam membangun. Framework yang digunakan adalah laravel agar lebih efisien dalam membangun sebuah situs web. Situs yang dibangun akan berupa situs dinamis dengan penyimpanan data menggunakan database, agar pihak gereja dapat dengan leluasa melakukan perubahan dalam jadwal acara. Dengan adanya situs yang dibangun untuk gereja, diharapkan informasi kepada jemaat akan diambil dari situs web. Sehingga saat ada perubahan informasi maka perubahan itu akan langsung terlihat dalam situs web dan dapat menjadi acuan bagi jemaat yang mencari info kegiatan. Pembangunan situs web menggunakan laravel dan metodologi prototyping membantu user dalam memperoleh gambaran mengenai situs web yang dibangun dan dapat melakukan penyesuaian sesuai dengan kebutuhan user.
\end{abstract}

Kata Kunci-Laravel, Prototyping, Website.

\section{Pendahuluan}

$\mathrm{G}$ ereja Reformed Injili Indonesia (GRII) yang berlokasi di jalan kertajaya memiliki beberapa jadwal kebaktian, masalah yang terjadi adalah ketika ada jadwal kebaktian yang berubah. Ketika jadwal kebaktian berubah hanya jemaat lokal yang mengetahui perubahan tersebut sedangkan jemaat cabang lain atau jemaat yang berasal dari kota lain dan sedang berada di surabaya tidak akan mengetahui perubahan tersebut dikarenakan perubahan hanya diumumkan di mimbar.

Masalah kedua adalah ketika berada dalam search engine maka jadwal kebaktian akan mengacu pada jadwal lama yang ditulis oleh orang pada situs web pribadi atau pada situs web gereja cabang lain. Jadwal pada gereja cabang lainpun memiliki masalah yang sama yakni ketika jadwal kebaktian berubah, informasi perubahan tersebut tidak langsung tersampaikan dan ketika informasi tersebut telah tersampaikan, perubahan jadwal pada situs web tidak

Maret 2020

Eric Sugiharto Honggara, Departemen Sistem Informasi, Institut Sains dan Teknologi Terpadu Surabaya, Surabaya, Jawa Timur, Indonesia (e-mail: ericsugiharto@stts.edu) dilakukan dengan segera karena menunggu penanggung jawab atau pembangun situs web untuk melakukan perubahan.

Masalah berikut yang muncul adalah ketika ada pengumuman atau acara khusus. Ketika ada pengumuman dan acara khusus maka banyak jemaat yang tidak mendapatkan informasi atau kesusahan dalam mendapatkan informasi, sehingga muncul misinformasi dan terdapat keluhan dari beberapa jemaat dan pengunjung karena masalah informasi yang tidak terbagikan.

Sehingga setelah didiskusikan dengan pihak pengurus GRII Kertajaya maka diperlukan sebuah situs web pribadi untuk GRII Kertajaya dalam melakukan publikasi perubahan jadwal GRII Kertajaya, pengumuman, dan penambahan jadwal acara baik yang khusus maupun jadwal acara umum. Selain itu diperlukan pula kemampuan untuk melakukan perubahan secara independen, sehingga bila terdapat perubahan dapat dilakukan dengan segera tanpa menghubungi programmer untuk melakukan perubahan.

\section{TINJAUAN PUSTAKA}

\section{A. Hypertext Markup Language (HTML)}

HTML adalah sebuah bahasa standar yag digunakan untuk membuat sebuah halaman web dan ditampilkan dalam penjelajah web, HTML dibuat oleh kolaborasi Tim BernersLee dengan Robert Cailliau pada akhir tahun 1990 dan digunakan dalam pembangunan web [1]. Hingga saat ini perkembangan dari HTML sudah mencapai HTML5.2 [2]. Sedangkan perkembangan HMTL 5.3 sedang dalam draft pengembangan.

\section{B. Cascading Style Sheet (CSS)}

CSS adalah bahasa yang digunakan dalam presentasi halaman web, termasuk warna, susunan tampilan dan jenis tulisan. CSS juga memampukan adaptasi presentasi sebuah web dalam berbagai macam tipe device dengan ukuran layar yang berbeda-beda, dari layar ukuran kecil, besar hingga tampilan dalam printer. CSS adalah bahasa yang berdiri sendiri atau tidak bergantung pada HTML dan bisa digunakan dengan bahasa manapun dengan basis XML. Pemisahan HTML dan CSS membuat perawatan sebuah situs web menjadi lebih mudah [1].

\section{Hypertext Preprocessor (PHP)}

PHP adalah bahasa pemprograman yang di desain untuk pembangunan sebuah situs web dan diciptakan oleh Rasmus Lerdorf yang dapat dimasukan dalam HTML [3]. PHP adalah sebuah bahasa yang sangat cocok digunakan dalam 
pembangunan sebuah situs web untuk bagian server yang mana digunakan secara umum untuk membangun halaman situs web yang dinamis.

\section{Laravel}

Laravel adalah kerangka kerja untuk membantu dalam pembangunan sebuah halaman situs web mengikuti arsitektur model-view-controller dan menggunakan utilisasi dari composer untuk mengatur ketergantungan [4]. Beberapa fitur dalam Laravel berbentuk modular paket sistem yang dapat saling terkait, dan perangkat yang membantu dalam membangun dan perawatan sebuah situs web. Beberapa modul Laravel yang digunakan dalam membantu pembangunan situs web GRII Kertajaya adalah CKEditor yang digunakan untuk membantu menulis artikel seperti pengumuman dan dapat melakukan perubahan dalam text seperti bold, italic dan pemberian poin agar membantu pengunjung situs web dalam membaca [5]. CKEditor adalah sebuah proyek open-source, yang berarti bahwa pemilik perangkat lunak tersebut memiliki hak penuh untuk mempelajari, mengubah dan mendistribusikan perangkat lunak tersebut ke siapapun dan dengan tujuan apapun.

\section{E. Bootstrap}

Bootstrap adalah kerangka kerja untuk CSS yang tidak berbayar untuk membantu dalam membuat sebuah tampilan tatap muka yang responsif untuk ukuran perangkat ponsel pintar. Kerangka kerja Bootstrap membantu konsistensi dalam pembangunan tatap muka. Bootstrap juga terintegrasi secara langsung dengan Laravel sehingga tidak pelu menuliskan kembali setiap kode CSS yang digunakan untuk membangun tatap muka [6].

\section{METODE}

Metode pembangunan perangkat lunak yang digunakan dalam penelitian ini adalah prototyping [6]. Prototyping adalah proses dimana pembangun perangkat lunak membuat contoh awal, model atau produk untuk menguji coba sebuah konsep atau proses. Pembangunan model atau purwarupa akan dilakukan berkali-kali hingga sesuai dengan kebutuhan pengguna dalam menjalankan tugas dan fungsi pokok. Prototype merepresentasikan fitur fungsional dari keseluruhan produk final. Keuntungan prototyping adalah mengurangi biaya dan waktu pengerjaan karena metode pembangunan ini akan mengurangi waktu dan biaya pengerjaan ulang karena adanya miskomunikasi atau misinformasi. Kedua meningkatkan keterlibatan pengguna, dengan prototype user dapat langsung memberikan tanggapan balik terhadap project yang dikerjakan dan spesifikasi sebuah proyek. Protoyping memerlukan user dan pembangun perangkat lunak bekerja sama dan berada dalam sebuah pikiran yang sama sehingga sangat diperlukan kejelasan dari tujuan atau fokus dari pembangunan perangkat lunak.

Berikut adalah langkah-langkah dalam mengerjakan pembangunan situs web

1) Melakukan analisa kebutuhan dan informasi mengenai situs web yang akan dibangun.

2) Membuat prototype dari analisa kebutuhan
3) Melakukan uji coba prototype pada pengguna dan berdiskusi mengenai perbaikan dan pengembangan selanjutnya

4) Bila hasil uji coba prototype belum sesuai maka akan kembali melakukan langkah 2, bila sudah selesai maka akan dilanjutkan membangun prototype halaman sistus web lain sesuai hasil analisa

5) Melakukan hosting pada situs web yang dibangun.

6) Melakukan penyesuaian situs web sesuai dengan tempat hosting.

\section{DESAIN SISTEM DAN IMPLEMENTASI}

Tujuan pembangunan perangkat lunak adalah membuat sebuah situs web untuk Gereja Reformed Injili Indonesia Surabaya cabang kertajaya dengan fitur utama sebagai berikut halaman pengumuman, halaman jadwal acara, halaman jadwal kebaktian yang bisa dilakukan secara dinamis tanpa menunggu pembangun situs web melakukan perubahan.

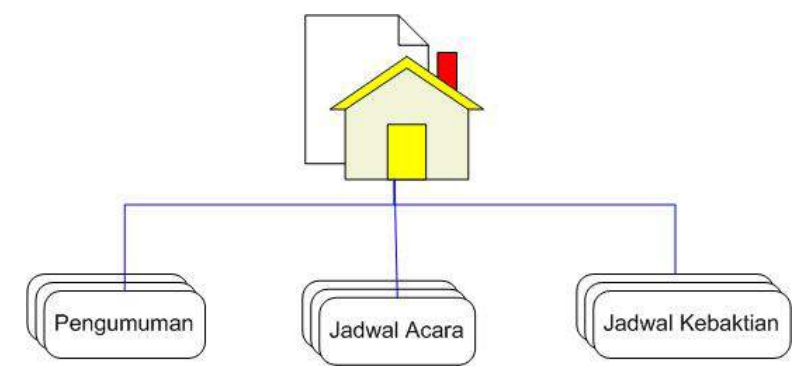

Gambar. 1. Konsep kebutuhan utama

Gambar 1 menggambarkan pengumuman, jadwal acara dan jadwal kebaktian akan terdiri dari beberapa halaman yakni, halaman untuk menampilkan data, pembuatan data, menghapus data dan halaman untuk mengubah data.

Selain ketentuan utama, terdapat beberapa halaman tambahan yang dibangun untuk melengkapi situs web antara lain sebagai berikut, visi misi GRII, doa, pengakuan iman penginjilan, profil hamba Tuhan dan ringkasan kotbah. Untuk halaman tambahan hanya profil hamba Tuhan dan ringkasan kotbah yang akan dibangun agar data yang dihasilkan bisa menjadi dinamis. Halaman tambahan seperti visi misi GRII, doa, pengakuan iman penginjilan akan dibuat halaman statis dan tidak boleh diubah tanpa persetujuan dari pihak GRII sehingga untuk melakukan perubahan maka pembangun situs web dihubungi untuk melakukan perubahan dan perubahan harus sesuai dengan persetujuan dari gembala GRII Kertajaya.

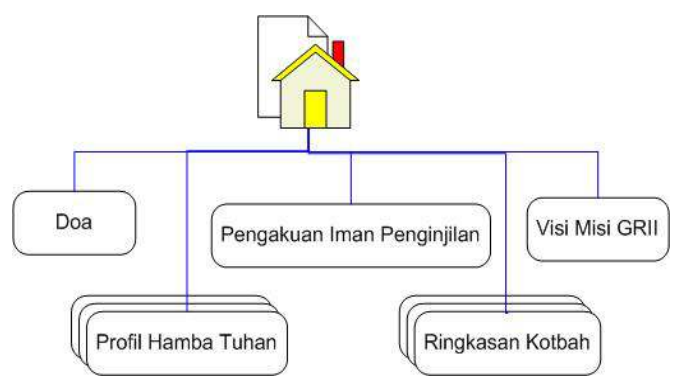

Gambar. 2. Konsep ketentuan tambahan 
Pada Gambar 2 halaman doa, pengakuan iman dan visi misi hanya akan terdiri dari 1 halaman, sedangkan untuk profil Hamba Tuhan dan ringkasan kotbah akan memiliki beberapa halaman untuk menampilkan, mengubah dan menghapus data.

Untuk pengguna dibagi menjadi beberapa hak akses, pertama adalah sekretariat yang akan melakukan pengisian, pengubahan dan penghapusan data pada halaman profil hamba Tuhan, pengumuman, jadwal acara, jadwal kebaktian. Kedua adalah penulis ringkasan kotbah yang diberi tugas oleh gereja untuk menulis pada halaman ringkasan kotbah. Pengguna terakhir adalah hamba Tuhan, yang akan melakukan pemeriksaan ringkasan kotbah dan memutuskan ringkasan kotbah yang bisa dipublikasikan atau perlu dilakukan perbaikan.

\section{A. Desain Sekretariat}

Sekretariat akan memiliki hak akses pada pengumuman, jadwal acara, jadwal kebaktian dan profil hamba Tuhan. Karena setiap pengumuman dan acara yang akan diadakan di GRII kertajaya akan melalui sekretariat terlebih dahulu.

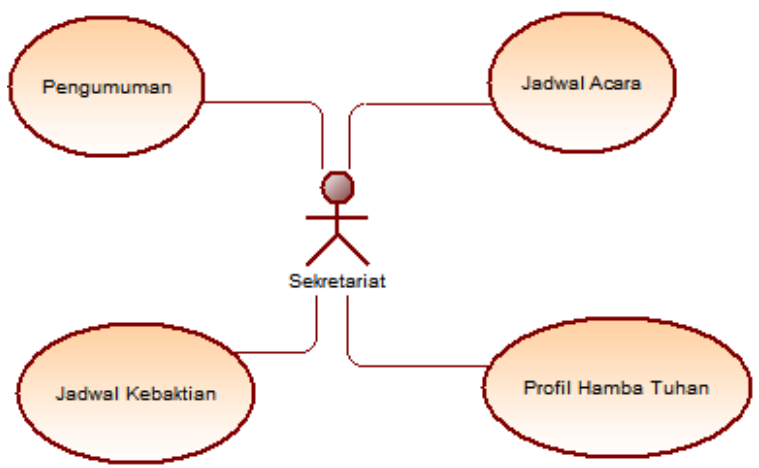

Gambar. 3. Use Case Sekretariat 1

Untuk jadwal kebaktian terdiri dari beberapa komponen yakni jam, hari kebaktian. Karena jadwal kebaktian adalah sesuatu yang rutin maka apabila ada perubahan acara akan dituliskan dalam pengumuman. Untuk pergantian data jadwal kebaktian dapat dilakukan di sekretariat dan disetujui dalam rapat pengurus serta oleh hamba Tuhan yang bertugas sebagai gembala sidang.

Kemudian pembeda dari Jadwal Kebaktian dan jadwal acara adalah jadwal acara terbagi menjadi 3 jenis yakni jadwal acara yang tidak rutin dari GRII Kertajaya, kedua jadwal acara GRII secara umum yang akan memakai tempat di GRII Kertajaya, ketiga adalah jadwal acara untuk nonGRII seperti sekolah logos atau kelas Sekolah Theologi Reformed Injili Surabaya yang menggunakan gedung dari GRII Kertajaya. Pembeda kedua dari jadwal kebaktian dengan jadwal acara adalah foto. Pada acara tertentu terdapat sebuah brosur yang diunggah sebagai foto. Terakhir dalam beberapa acara bisa terdapat biaya yang harus disiapkan oleh orang yang ingin mengikuti acara tersebut. Pada pembangunan prototype terakhir dalam jadwal acara ditemukan beberapa kendala seperti acara kebutuhan akan acara rutin GRII diluar kebaktian. Format dari acara rutin diluar hari minggu dan memerlukan inputan yang sama persis dengan jadwal kebaktian, bedanya adalah dalam jadwal acara rutin GRII akan ada no kontak yang bisa dihubungi untuk acara tersebut. Sehingga Use Case dari sekretariat berubah menjadi.

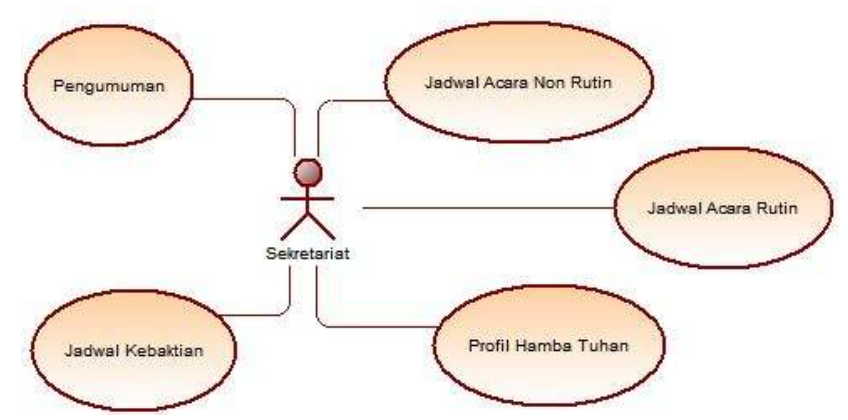

Gambar. 4. Use Case Sekretariat 2

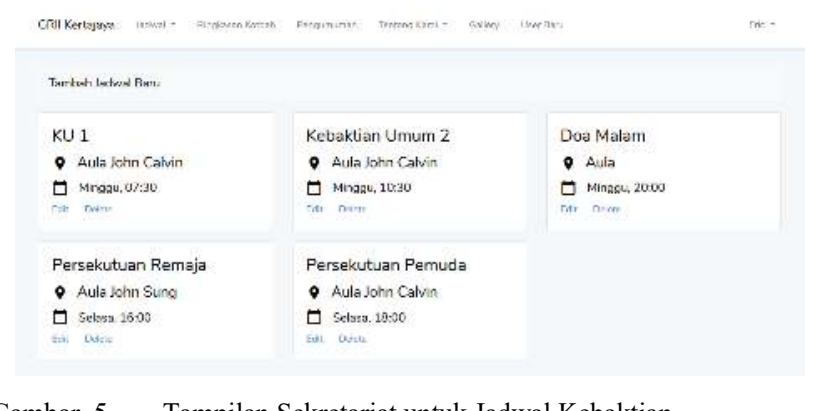

Gambar. 5. Tampilan Sekretariat untuk Jadwal Kebaktian

Pengumuman digunakan untuk memberitahu jemaat bahwa terdapat pengumuman yang dikeluarkan oleh GRII Kertajaya, untuk pengumuman ini akan ditempatkan pada halaman pengumuman dan akan ditempatkan pada halaman depan apabila pengumuman tersebut dirasa penting seperti jadwal kebaktian rutin digabung menjadi 1 jadwal kebaktian. Sehingga di dalam pengumuman akan ada fitur untuk memberikan sebuah marka apakah pengumuman tersebut ditampilkan di halaman depan atau tidak. Kemudian untuk pengumuman juga dapat diberikan pengaturan agar hilang secara sendirinya setelah waktu yang ditentukan habis.

Profil hamba Tuhan akan diisi pula oleh sekretariat dan digunakan agar jemaat atau pengunjung situs web mengetahui siapa hamba Tuhan yang melayani di GRII Kertajaya dan bisa mengenal hamba Tuhan melalui deskripsi yang dituliskan. Profil hamba Tuhan tidak diberikan kepada user hamba Tuhan karena tidak semua hamba Tuhan akan dapat mengakses situs web sehingga diputuskan pengisi profil hamba Tuhan adalah sekretariat. Profil hamba Tuhan juga dibuat dinamis dikarenakan GRII pusat dapat sewaktu-waktu mengutus atau melakukan mutasi kepada hamba Tuhan yang ditetapkan pada cabang.

\section{B. Desain Penulis Ringkot}

Untuk ringkasan kotbah akan ada 2 user. Pertama, adalah penulis ringkasan kotbah, dimana hasil ringkasan kotbah tidak akan langsung ditampilkan pada halaman ringkasan kotbah tetapi akan dilakukan review oleh user hamba Tuhan yang ditugaskan dan disetujui terlebih dahulu. User hamba 
Tuhan memiliki hak akses yang lebih tinggi daripada penulis ringkasan dengan case tambahan untuk mengubah status menjadi disetujui dan membatalkan ringkasan kotbah yang telah disetujui kembali menjadi dalam review.

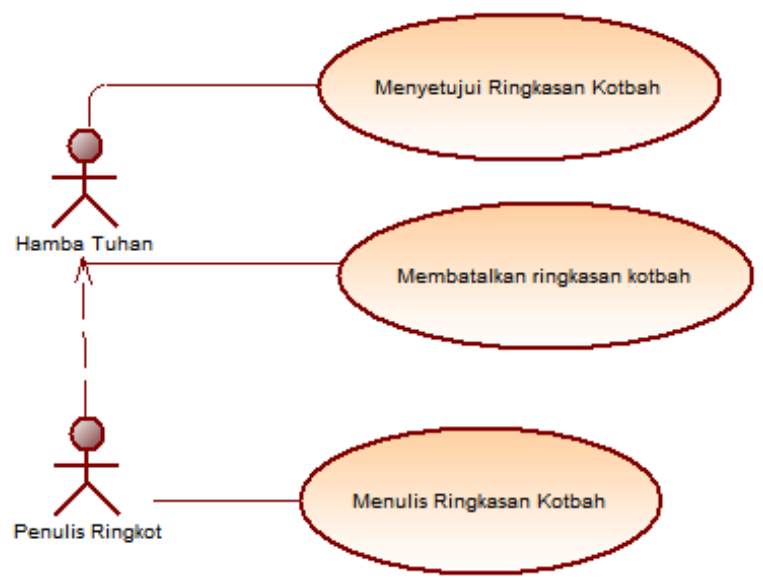

Gambar. 6. Use Case Ringkasan Kotbah

Pada gambar 6 tergambar hak akses dari penulis ringkasan kotbah. Spesialisasi dari aktor penulis ringkasan kotbah adalah Hamba Tuhan yang mempunyai hak akses untuk menyetujui ringkasan kotbah atau membatalkan ringkasan kotbah. Untuk alur kerja ringkasan kotbah ada beberapa tahap, dimulai dari pihak audio video gereja mengambil rekaman dari alat perekam gereja dan mengirimkan ke orang-orang yang ditunjuk oleh gereja. Setelah mengerjakan ringkasan kotbah tersebut maka hasil akan dikirimkan melalui email atau whatsapp. Kemudian hasil ringkasan kotbah akan diperiksa kembali oleh hamba Tuhan yang telah ditunjuk dan akan dinilai apakah hasil ringkasan kotbah tersebut akan dipublikasikan atau tidak. Pada tahap ini sering terjadi miskomunikasi atau kesusahan mencari ringkasan kotbah yang telah dibuat, karena hamba Tuhan menerima banyak sekali email dan wa setiap harinya. Solusi yang diberikan dalam situs web akan membantu mengatasi permasalahan tersebut dikarenakan penulis ringkasan kotbah dan hamba Tuhan akan melakukan hal ini di tempat yang sama. Ringkasan kotbah akan dibagi menjadi 2 yakni ringkasan kotbah yang belum diperiksa dan ringkasan kotbah yang telah dipublikasikan.

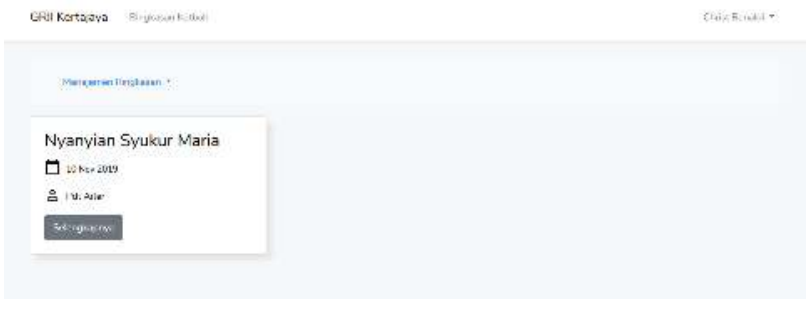

Gambar. 7. Tampilan Penulis Ringkasan Kotbah

Pada ringkasan kotbah dipasang sebuah modul tambahan di luar Laravel dengan nama CKEditor. Pemasangan CKEditor hanya perlu menuliskan "npm install --save ckeditor" pada terminal yang ada di Laravel. Pemasangan pada halaman situs hanya menambahkan sebuah html tag div dengan sebuah id yang diberi nama editor kemudian menggunakan javascript untuk mengganti tag div tersebut dengan CKEditor. Maka akan muncul sebuah tampilan yang dapat digunakan untuk menulis sebuah artikel dengan fitur seperti yang ada di dalam editor text seperti bold, italic, bullet dan numbering seperti yang ada pada gambar 8 .

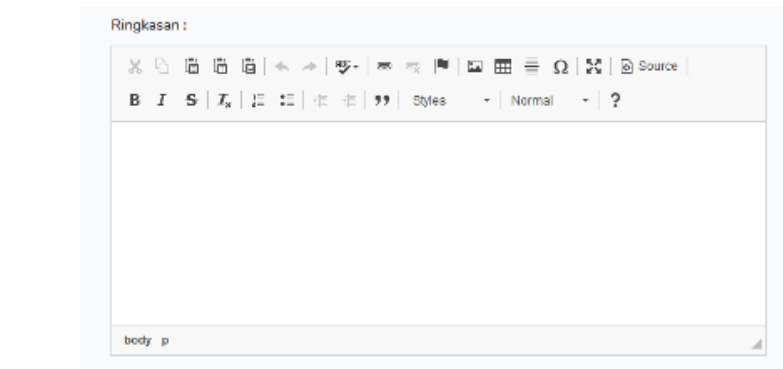

Gambar. 8. Tampilan CKEditor dalam Penjelajah Web

Hasil dari tulisan di dalam CKEditor akan disimpan dalam bentuk HTML tag dalam database sehingga tidak perlu penyimpanan khusus. Untuk membaca hasil dari CKEditor memerlukan package form dari Laravel collective, agar hasil tidak ditampilkan sesuai dengan yang tersimpan dalam database tapi setiap html tag turut terbaca.

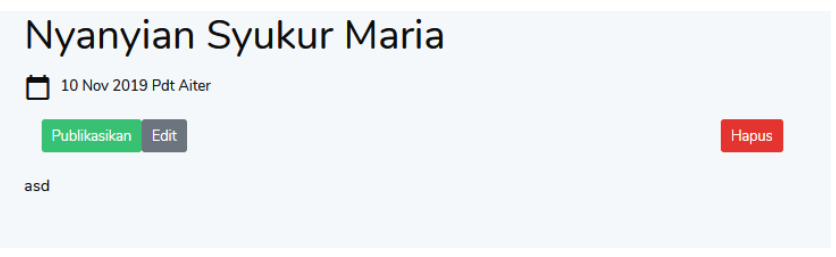

Gambar. 9. Fitur Khusus User Hamba Tuhan

Pada gambar 9 adalah fitur khusus hamba Tuhan yang memeriksa ringkasan kotbah memiliki fitur khusus dalam tampilan ringkasan kotbah. Perbedaan tersebut ada dalam tombol "Publikasikan" untuk membuat ringkasan kotbah tersebut tampil di dalam situs web. Perbedaan berikutnya adalah tombol "Edit" untuk mengubah konten dari kotbah tersebut, termasuk membatalkan publikasi dari kotbah sehingga kotbah tidak dimunculkan pada situs web. Terakhir adalah "hapus" untuk menghapus kotbah tersebut dikarenakan konten diisi sembarangan.

\section{KESIMPULAN}

Selama proses pengerjaan situs web maka dapat diambil beberapa kesimpulan sebagai berikut.

1) Penggunaan Laravel dalam membangun situs web sangat membantu dalam pembangunan Create, Read, Update, Delete (CRUD), halaman login untuk masuk ke dalam situs dan penambahan modul khusus yang dibutuhkan oleh pengguna seperti CKEditor tanpa harus membuat sendiri dari awal.

2) Kekurangan Laravel adalah ukuran file akhir jauh lebih besar dibandingkan pembangunan situs web tanpa menggunakan Laravel, hal ini karena Laravel memiliki beberapa modul yang akan ikut terunggah dalam tempat hosting. Apabila ingin memperkecil ukuran file yang akan dihosting maka perlu menghapus modul yang tidak 
digunakan tapi hal ini adalah sesuatu yang susah dilakukan dikarenakan setiap modul tersebut tersambung dalam package dan hubungan antar package sangat banyak sehingga sangat susah bila ingin menghapus package yang ada. Salah satu solusi adalah menghapus folder node_modules yang muncul dikarenakan menjalankan perintah "npm run dev" untuk membuat ssas dapat diimplementasikan.

3) Hosting dari Laravel mudah, akan tetapi terdapat masalah dalam penyimpanan aset dan resource gambar yang diunggah dalam situs. Sehingga sangat direkomendasikan menggunakan aset yang bisa digunakan online. Untuk resource gambar perbaikan yang dapat dilakukan adalah menggunakan terminal di tempat hosting agar menjadikan folder resource gambar pada sebuah folder yang sama seperti pada saat pembangunan situs dalam lokal.

4) Bootstrap membantu dalam membangun tampilan tatap muka dan memberikan kemudahan dalam tampilan perangkat ponsel pintar. Sehingga hal ini sangat mempersingkat waktu untuk membangun tampilan tatap muka.

\section{DAFTAR PUSTAKA}

[1] T. W. W. W. Consortium(W3C), "HTML \& CSS - W3C," The World Wide Web Consortium, [Online]. Available: https://www.w3.org/standards/webdesign/htmlcss. [Accessed 19 November 2019].

[2] T. W. W. W. Consortium(W3C), "HTML 5.2," 14 Desember 2017. [Online]. Available: https://www.w3.org/TR/2017/REC-html5220171214/. [Accessed 14 November 2019].

[3] The PHP Documentation Group, "PHP:History of PHP - Manual," The PHP Group, [Online]. Available: https://www.php.net/manual/en/history.php.php. [Accessed 2019 November 2019].

[4] T. Otwell, "Installation - Laravel - The PHP Framework," Laravel LLC, [Online]. Available: https://laravel.com/docs/6.x. [Accessed 2019 November 14].

[5] CKSource, "Basic CKEditor Concepts - CKEditor 4 Documentation," CKSource, [Online]. Available:

https://ckeditor.com/docs/ckeditor4/latest/guide/dev_basics.html. [Accessed 14 November 2019].

[6] M. Otto, "Bootstrap," Bootstrap, [Online]. Available: Getbootstrap.com. [Accessed 1511 2019].

[7] M. F. Smith, Software Prototyping: Adoption, Practice and Management, Michigan: McGraw-Hill, 1991, p. 200.

Eric Sugiharto Honggara lahir di Surabaya, Jawa Timur, Indonesia, pada tahun 1990. Menyelesaikan studi S1 di program studi Sistem Infomasi Bisnis STTS pada tahun 2012. Eric menyelesaikan studi magister pada jurusan Teknologi Informasi STTS. Bidang penelitiannya adalah sistem informasi, Digital marketing dan user experience. 